\title{
Solid particles in the tropical lowest stratosphere
}

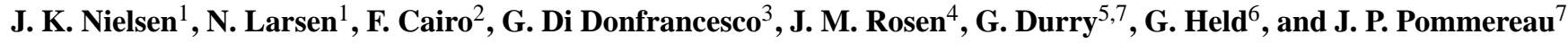 \\ ${ }^{1}$ Danish Meteorological Institute, Lyngbyvej 100, 2100 Kbh. Ø, Denmark \\ ${ }^{2}$ Institute for Atmospheric Science and Climate, CNR, Via del Fosso del Cavaliere 100, 00133 Rome, Italy \\ ${ }^{3}$ Italian National Agency for New Technologies, Energy and Environment, ENEA C. R. Cassaccia, Via Anguillarese 301, \\ 00060 Rome, Italy \\ ${ }^{4}$ University of Wyoming, Department of Physics and Astronomy, Laramie, Wyoming 82071, USA \\ ${ }^{5}$ Groupe de Spectrometrie Moleculaire et Atmospherique, CNRS, Universite de Reims, 51687 Reims, France \\ ${ }^{6}$ Instituto de Pesquisas Meteorológicas, Universidade Estadual Paulista, CX Postal, 281 17015-970 BAURU, S. P., Brasil \\ ${ }^{7}$ CNRS, Institut Pierre Simon Laplace, Service d'Aeronomie, B.P. 3, 91371 Verrieres le Buisson Cedex, France
}

Received: 1 June 2006 - Published in Atmos. Chem. Phys. Discuss.: 25 September 2006

Revised: 16 January 2007 - Accepted: 4 February 2007 - Published: 12 February 2007

\begin{abstract}
We report in situ and remote observations proving occasional occurrence of solid particles in the tropical lowest stratosphere, $200 \mathrm{~km}$ from deep convective events. The particles were found during field campaigns in Southeast Brazil (49.03 W 22.36 S). They occur in the altitude range from 17.5 to $20.8 \mathrm{~km}$, at temperatures up to at least $10 \mathrm{~K}$ above the expected frost point temperature. While stability of ice particles at these altitudes is unexpected from a theoretical point of view, it is argued that these observations are indications of tropospheric air masses penetrating into the stratosphere during convective overshoots. It is argued that the intrusion of tropospheric air must have carried a large amount of water with it, which effectively hydrated the lowest stratosphere, and consequently suppressed sublimation. This conclusion is further supported by a separate water vapor mixing ratio profile obtained at the same observation site.
\end{abstract}

\section{Introduction}

In the global tropospheric-stratospheric mass exchange pattern, known as the Brewer Dobson circulation, air enters the stratosphere mainly through the tropical tropopause (Holton et al., 1995). During ascent through the Upper Troposphere/Lower Stratosphere (UTLS) air masses lose most of their water content through sedimentation of ice particles at the extremely cold temperatures near the tropopause. The detailed mechanisms of this dehydration, or "freeze drying" process are of great importance for understanding the stratospheric water budget.

Two main paradigms can be identified in the ongoing discussion about the nature of the dehydration processes. In

Correspondence to: J. K. Nielsen

(jkn@dmi.dk) the first paradigm, dehydration happens as a slow large-scale process where air masses are transported through the cold point tropopause on their way to the stratosphere. Newell and Gould-Stewart (1981) pointed at the tropopause over the Maritime Continent as the place where air probably enters the stratosphere and is dehydrated. They noted that the temperature at the maritime tropopause at $190.8 \mathrm{~K}$ corresponds to a stratospheric water content of $3.5 \mathrm{ppmv}$.

In the second paradigm, dehydration happens in connection with deep convective systems. Danielsen (1982) proposed that air enters the stratosphere in overshooting turrets of tropical thunderstorms. He suggested that the anvils remaining from deep convective events act as "dehydration engines". Sherwood and Dessler (2001) proposed that air masses penetrate into the so called Tropical Tropopause Layer (TTL, 50-150 hPa) by overshooting convective events. During this process air undergoes dehydration due to extremely low temperatures in the updrafts. In the detrainment from the updraft, air masses are mixed with air masses at the level of detrainment, before they stabilize at a lower level. Thereafter the air proceeds in a very slow ascent through the TTL, where it undergoes further mixing with new convective overshoots.

However, it has been argued from thermodynamic grounds by Folkins et al. (1999) that convective events seldom rise into the TTL. Likewise, Küpper et al. (2004) conclude on the basis of cloud resolving simulations, that vertical transport within overshooting cumulus is insignificant in the TTL. In line with Potter and Holton (1995); Fueglistaler et al. (2004); Hartmann et al. (2001); Gettelman et al. (2000), they conclude that dehydration mainly happens during slow ascent through a cold tropopause. Several studies address the details of this type of process. It has been demonstrated in microphysical simulations by Jensen et al. (2001) how such

Published by Copernicus GmbH on behalf of the European Geosciences Union. 


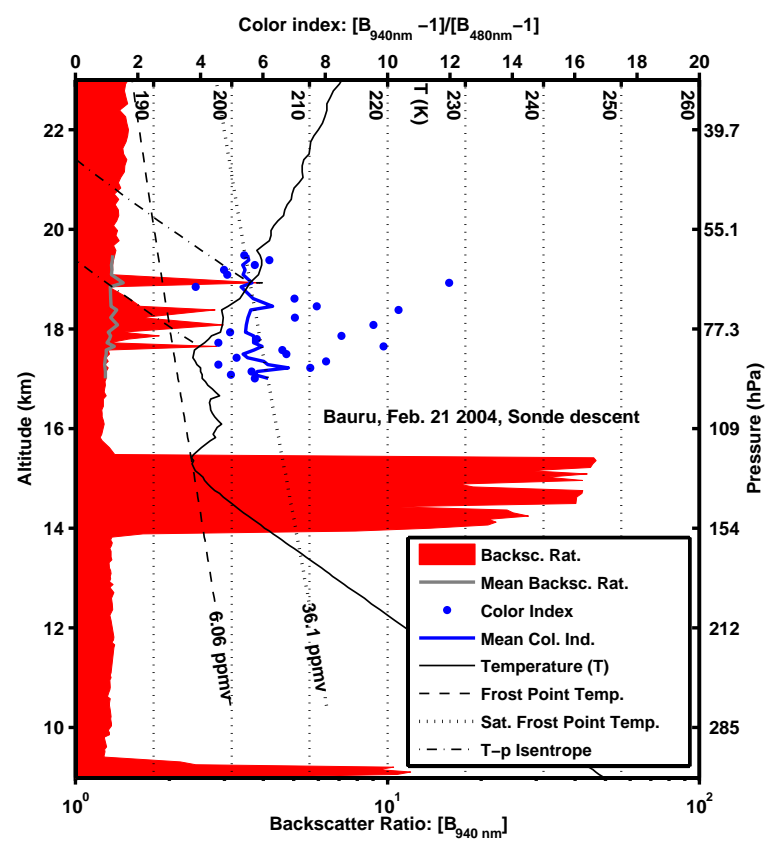

Fig. 1. O1. Backscatter sounding recorded on February 21, 2004 01:00 to 02:00 on descent, at $49.03 \mathrm{~W} 22.36 \mathrm{~S}$. Red filled function: Backscatter ratio at $940 \mathrm{~nm}\left(B_{940 \mathrm{~nm}}\right)$. The backscatter ratio is given by $S=\left(B_{R}+B_{A}\right) / B_{R}$, where $B_{R}$ is the molecular backscatter coefficient, and $B_{A}$ is the aerosol backscatter coefficient. Thick grey curve: Average backscatter ratio for all flights (including both ascent and descent). The whole series counts 10 flights, launched in February 2004 from the same location. Blue dots: Color index (i.e., $\left.\frac{B_{940 n m}-1}{B_{480 n m}-1}\right)$ for Feb 21 flight. Thick blue curve: Average color index for all soundings. Thin black curve: Temperature (K). Dashed black curve: Estimate of frost point temperature $\left(T_{\text {ice }}\right)$. $T_{\text {ice }}$ is estimated from the flight temperature and pressure data by assuming saturation of water vapor with respect to ice at all altitudes (an overestimate), and then finding the minimum water vapor mixing ratio. In this case a water vapor mixing ratio minimum of $6.06 \mathrm{ppmv}$ is found at $15.3 \mathrm{~km}$, and this mixing ratio is used to calculate $T_{\text {ice }}$. The dotted black curve is the frost point temperature calculated by assuming a water vapor mixing ratio of $36.1 \mathrm{ppmv}$, corresponding to saturation with respect to ice at the highest altitude with particle occurrence. The dash-dotted curves marks the isentropes which would have to be followed if air is cooled through expansion.

dehydration may work. Potter and Holton (1995) showed, with a bulk microphysical model, that buoyancy waves generated from convection may form cirrus which enhance dehydration of the lower stratosphere. Hartmann et al. (2001); Holton and Gettelman (2001), as well as Gettelman et al. (2000), pointed out that cirrus residing above convective systems can maintain radiative stability because of anvils shielding the radiation from below. They proposed that air is horizontally advected into extremely cold large areas positioned over convective activity in the western Pacific, and thereby is dehydrated. This concept was incorporated into a broader picture by Fueglistaler et al. (2004), showing that air is lifted into the TTL mainly above the western Pacific, and thereafter distributed globally in the TTL, where it circulates for a long time and eventually gets dehydrated as it passes through the coldest area of the TTL, also over Western Pacific. In Fueglistaler and Haynes (2005) it is demonstrated that seasonal and interannual variability of lower stratospheric water vapor may be explained in this view. The analysis of (Fueglistaler et al. (2004); Fueglistaler and Haynes (2005)) was based on ECMWF-trajectories, and it showed that convective overshooting must be of secondary importance as a dehydration mechanism. A similar approach, based on NCEP-trajectories and detailed microphysics (Jensen and Pfister, 2004) also leads to effective dehydration, suggesting a need for an additional water source which could be deep convection.

On the other hand, deep convective penetration into the TTL happens occasionally (Alcala and Dessler, 2002; Adler and Mack, 1986; Ebert and Holland, 1992; Simpson et al., 1993; Knollenberg et al., 1993), but it is unclear what the role of such events is with respect to dehydration of air entering into the stratosphere. Radiometer measurements $\mathrm{Wu}$ et al. (2005) show that convectively lofted ice particles contribute significantly to the total water content at the tropical cold point, and evidence for convection as source of stratospheric water has been derived from measurements of deuterated water in the TTL in e.g. Moyer et al. (1996). The question is, whether convective events act like additional dehydration parallel to cooling by slow ascent, or if convective events do in fact hydrate the lower stratosphere. Both cases could include the additional feature of convective events enforcing the dehydration by emission of buoyancy waves, which temporarily may decrease temperatures around the tropopause.

Here we present in-situ and remote measurements of very dilute particle occurrences above the TTL far away from any convective events. We argue that these particles most likely were emitted from a thunderstorm several hours earlier, and we discuss the possible implications for the role of deep convection in the troposphere to stratosphere transport.

\section{Data collection and observations}

The HIBISCUS (Impact of tropical convection on the upper troposphere and lower stratosphere (UTLS) at global scale) campaigns took place in Bauru, Brazil, in 2001, 2003 and 2004 (Pommereau, 2004). These campaigns included local balloon-borne measurements of aerosols and chemical species and ground-based lidar measurements. Here we present two specific particle observations, supported by a series of ozone soundings. The local support included two Sband Doppler radars (beam width $2^{\circ}$ ), which provided observations of rainfall intensity and heights of the echo tops. The uncertainty of cloud height estimates is within $1 \mathrm{~km}$ at long ranges, but considerably less for storms closer to the radar. 


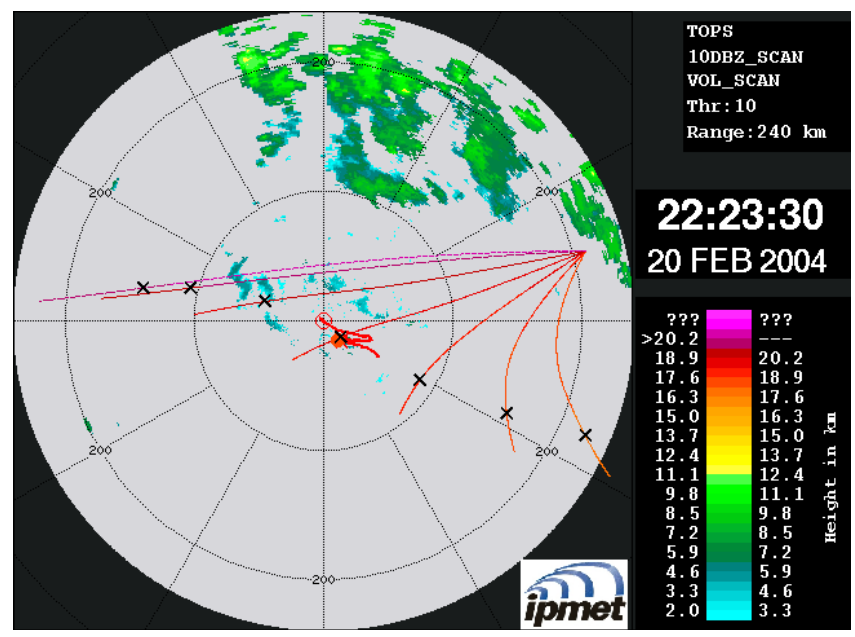

Fig. 2. O1. Radar image of echo top altitude (10 dBZ radar reflectivity threshold) observed at the time when the particles were observed. The balloon (red thick trajectory) was launched at the location of the Bauru Radar (center). The radar range is $240 \mathrm{~km}$. There are no convective cells in the vicinity of the observation. The multi colored lines are trajectories, derived from ECMWF operational analysis, initiated approximately at the center of a storm $5.5 \mathrm{~h}$ before the observation, at altitudes 18.5, 18.9, 19.4, 19.9, 20.5, 21.1, and $21.8 \mathrm{~km}$. A fall speed of $0.028 \mathrm{~m} / \mathrm{s}$, corresponding approximately to a particle radius of $10 \mu \mathrm{m}$, is assumed. The color shading of the trajectories indicates the altitude according to the same scale as the echo top. The red filled bullet indicates the observation point.

The first observation (O1) was made in situ on 21 Februry 2004, 01:19 UT at 17.7 to $18.9 \mathrm{~km}$ altitude with a balloonborne Wyoming backscatter sonde during descent. This instrument detects backscatter signals at wavelengths $940 \mathrm{~nm}$ and $480 \mathrm{~nm}$ (see Rosen and Kjome (1991) for a technical description of the Wyoming backscatter sonde). Figure 1 shows some details of O1. The backscatter ratio at $940 \mathrm{~nm}$, plotted as a filled red curve, shows values bigger than the background in the altitude range 17.7 to $18.9 \mathrm{~km}$. The observation was done on the descent of one flight out of a total of ten flights, all performed in February 2004. No Wyoming backscatter sondes were flown during the pre-campaign in 2001. No particles were observed near $18 \mathrm{~km}$ on the ascent. We consider the possibility that the balloon should completely scavenge the particle layer on the ascent as being very unlikely, since the balloon is only in physical contact with a thin layer of air near its own surface. The fact that the layer was not observed on the backscatter sonde's ascent 30 min earlier suggests that it is of limited horizontal extent. The thick grey line shows the average backscatter ratio above the TTL from all flights including the highlighted one. This proves the existence of particles different from the background aerosols in an altitude range which lies just above the top of the TTL. The temperature (thin black line) in this altitude interval ranges from 195.9 to $202.4 \mathrm{~K}$. To illustrate why

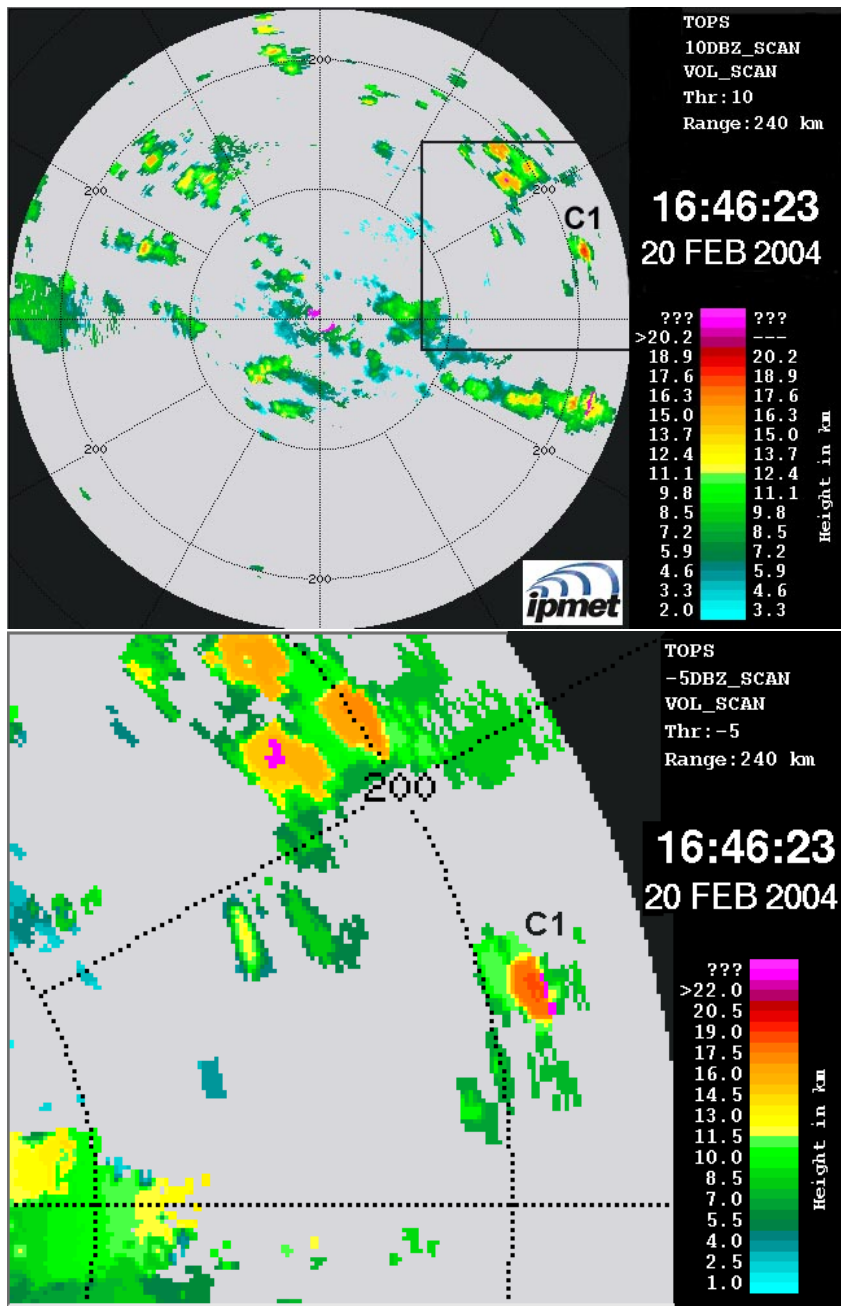

Fig. 3. (a) Same as in Fig. 2, $5 \mathrm{~h}$ and 37 min earlier. (b) Enlargement of the area from which the sampled airmasses originate. This map is made with a $-5 \mathrm{dBZ}$ radar reflectivity threshold.

this observation is unexpected, we have estimated the frost point temperature ( $T_{\text {ice}}$, dashed black line) by assuming a water vapor mixing ratio of $6.06 \mathrm{ppmv}$. This is the lowest water vapor mixing ratio deduced from the temperature and pressure profiles, by assuming saturation of water vapor with respect to ice. The value of $6.06 \mathrm{ppmv}$ is an overestimate of the water vapor mixing ratio compared to normal values (24 ppmv) at the bottom of the stratosphere, and the air parcels above the TTL had probably not passed through the local tropopause which was sampled by the balloon, in this case. The $T_{\text {ice }}$ estimate should be considered as a maximum value for this property, which illustrates why the presence of particles above the TTL is surprising. Air masses at these high altitudes are expected to be subsaturated. The dotted black line is the frost point temperature calculated by assuming a water vapor mixing ratio of $36.1 \mathrm{ppmv}$, the value corresponding to saturation with respect to ice at $18.9 \mathrm{~km}$. The color index 


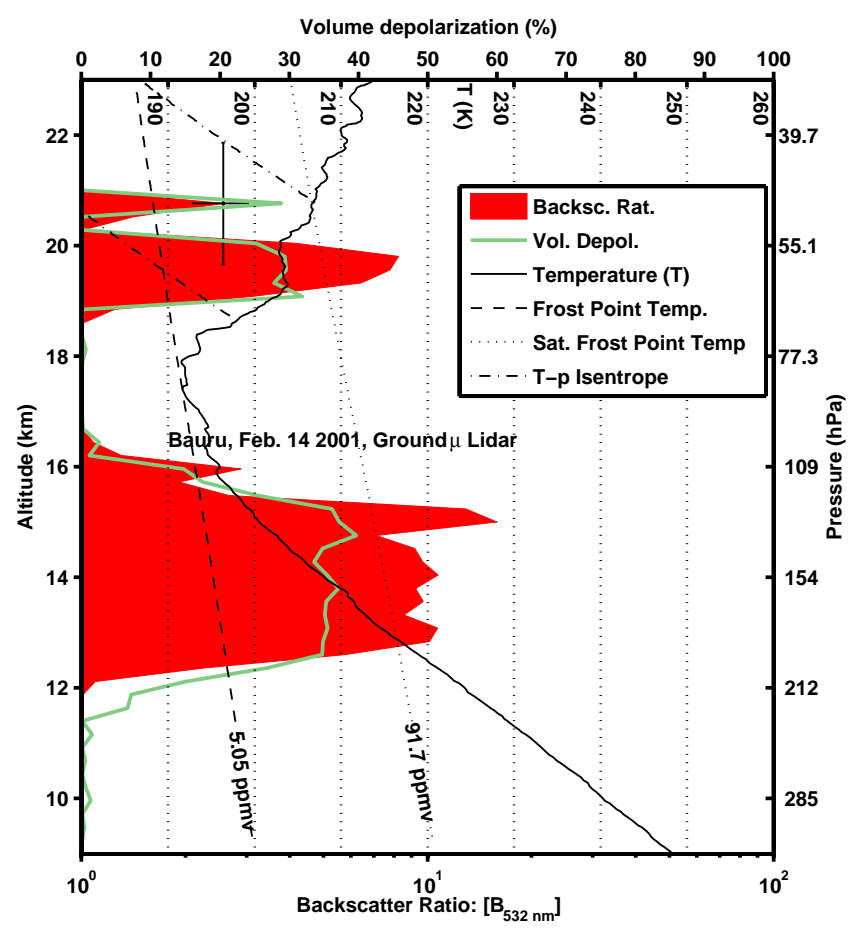

Fig. 4. O2. Backscatter data recorded with the $532 \mathrm{~nm} \mu$-Lidar from ground on 14 February 2001, at $49.03 \mathrm{~W} 22.36 \mathrm{~S}$. Filled red function: Backscatter ratio (same parameter as in Fig. 1, just another wavelength). Green curve: Volume depolarization $\frac{B_{\perp}}{B_{\|}}$(perpendicular component divided by parallel component of backscattering signal), where $B=B_{R}+B_{A}$ is the sum of molecular and aerosol backscattering coefficients. The backscatter signals from high altitude were present for approximately $15 \mathrm{~min}$, and the plots represent averages over this time interval. Thin black curve: Temperature recorded on 13 February 22:00 UT. Dashed black curve: Frost point temperature calculated in the same manner as in Fig. 1. Dotted black curve: Frost point temperature calculated by assuming a water vapor mixing ratio of $91.7 \mathrm{ppmv}$, corresponding to saturation with respect to ice at the highest altitude of particle occurrence. The dash-dotted curves mark the isentropes which have to be followed if air is cooled through expansion.

(blue dots in Fig. 1) contains information about particle sizes, which will be discussed further in Sect. 3. O1 is particularly interesting because it was supported by continuous radar observations during the whole mission (Figs. 2 and 3). These radar observations show that there were no deep convective events within a radius of $100 \mathrm{~km}$ from the observation during the flight (Fig. 2). We shall interpret the implications of this fact in the discussion below.

The second observation (O2, Fig. 4) was done on 14 February 2001 in the early evening, during the HIBISCUS pre-campaign with a $532 \mathrm{~nm} \mu$-lidar (see Di Donfrancesco et al. (in press) for a technical description of the $\mu$-lidar). In the altitude range $18.8-20.8 \mathrm{~km}$ optically thin particle layers were observed. The volume depolarization, which is non-

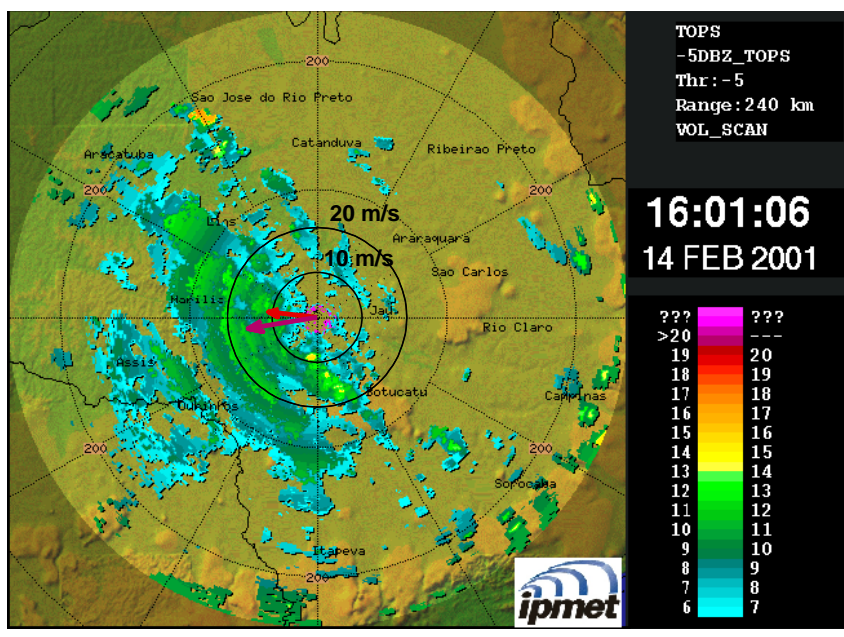

Fig. 5. O2. Radar image of echo top altitude ( $-5 \mathrm{dBZ}$ radar reflectivity threshold) observed at 16:01, local time, on 14 February 2001 from Bauru. The radar range is $240 \mathrm{~km}$. Note the area of convective activity in the eastern part of the radar range. The arrows in the center show the ECMWF operational analysis wind over Bauru on 14 February 2001, 15:00 local time, at 17, 19 and $21 \mathrm{~km}$ altitude (their color refers to the same colorbar as the cloud top altitudes). Please note that the 2 bold circles delineate wind speed in $\mathrm{m} / \mathrm{s}$, while from the outer circles indicate the 100 and $200 \mathrm{~km}$ distance, respectively, from the Bauru radar.

zero in the same altitude interval, indicates that the particles were non-spherical, i.e. solid. $\mathrm{O} 2$ was done during a ground based test-run of the $\mu$-lidar, and unfortunately the absolute time of this measurement is not known. There are no in situ ozone/temperature measurements in connection to $\mathrm{O} 2$. This is why $\mathrm{O} 2$ is not analyzed in so great detail as $\mathrm{O} 1$ in the following. During HIBISCUS the $\mu$-lidar was flown on balloons three times, and in none of these flights any aerosol anomalies were observed above the TTL. O2 is remarkable because the range where particles were observed extends to very high altitudes. The backscatter ratio is also larger than in O1. Generally the backscatter ratio is smaller at $532 \mathrm{~nm}$ than at $940 \mathrm{~nm}$, for a given particle distribution, so the larger lidar backscatter ratio indicates larger number density or larger particle radius in $\mathrm{O} 2$ than in $\mathrm{O} 1$. The horizontal extension of this phenomenon must have been limited, since the signal was only there for a approximately $15 \mathrm{~min}$, corresponding to a horizontal extend of around $10 \mathrm{~km}$. The local meteorological situation was very similar to that of 01 . An area of convective activity was located east of Bauru in the early afternoon and the steady easterly in the lowest stratosphere transported airmasses from this region to the area above Bauru at $18-20 \mathrm{~km}$ altitude during the early evening when $\mathrm{O} 2$ was performed (see Fig. 5). The convective area around Bauru at 16:01 local time has nothing to do with the observation because it does not reach the relevant altitudes, and if it did it would have been transported away by the stratospheric wind 


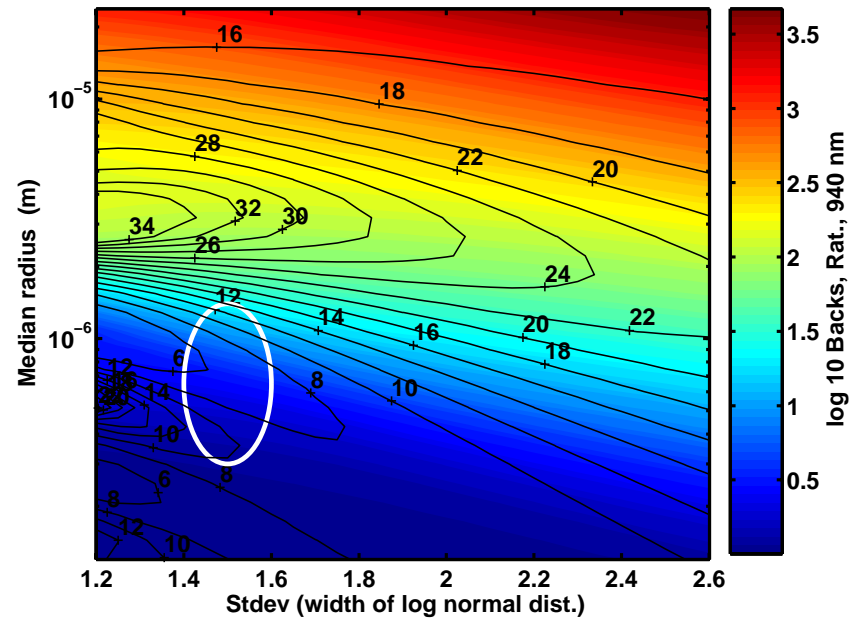

Fig. 6. Backscattering parameters for different log-normal size distributions characterized by their median radius, and width (stdv). Color map: Backscatter ratio $B=\left(B_{R}+B_{A}\right) / B_{R}$ at $940 \mathrm{~nm}$. Black contours: Color index $\frac{B_{940 \mathrm{~nm}}-1}{B_{480 \mathrm{~nm}}-1}$. Properties are calculated for assumed particle density of $10^{6}$ particles per $\mathrm{kg}$ air, temperature 200 $\mathrm{K}$, and pressure $100 \mathrm{hPa}$. The area inside the white ellipse indicates a reasonable guess of the log-normal parameters, guided by the observed color index.

before $\mathrm{O} 2$ was performed. The area from which the observed particles could originate is at the easterly rim of the radar range.

\section{Number density and composition.}

Considering O1, we first note that the increase in color index accompanying the particles around $18-19 \mathrm{~km}$ indicates that the particles were larger than the background aerosol (Schreiner et al., 2003). Particle sizes cannot be derived uniquely from the color index, but assuming a log-normal size distribution (stdv 1.5) of ellipsoid ice particles with aspect ratio 1.05 , one can make a crude estimate of the median radius. Utilizing the T-matrix method of Mishchenko and Travis (1998), the backscatter ratio and color index for a range of log-normal standard deviations and median radius values are mapped in Fig. 6. From Fig. 1 we see that the high-altitude particles have a color index between 7 and 12. The color index cannot vary much for liquid aerosols in the stratosphere, since their size distribution responds only weakly to changes in humidity. In fact experience from numerous backscatter soundings shows that background liquid aerosols always yield a color index around 6, and furthermore, the color index does not fluctuate as much for liquid aerosols as for solid particles, which can have all kinds of size-distributions. Solid particles typically shows a color index around 10 with much more variability (as is also seen in O1). This pattern is robust for both arctic and tropical aerosols, and it holds for in situ formed aerosols as well as

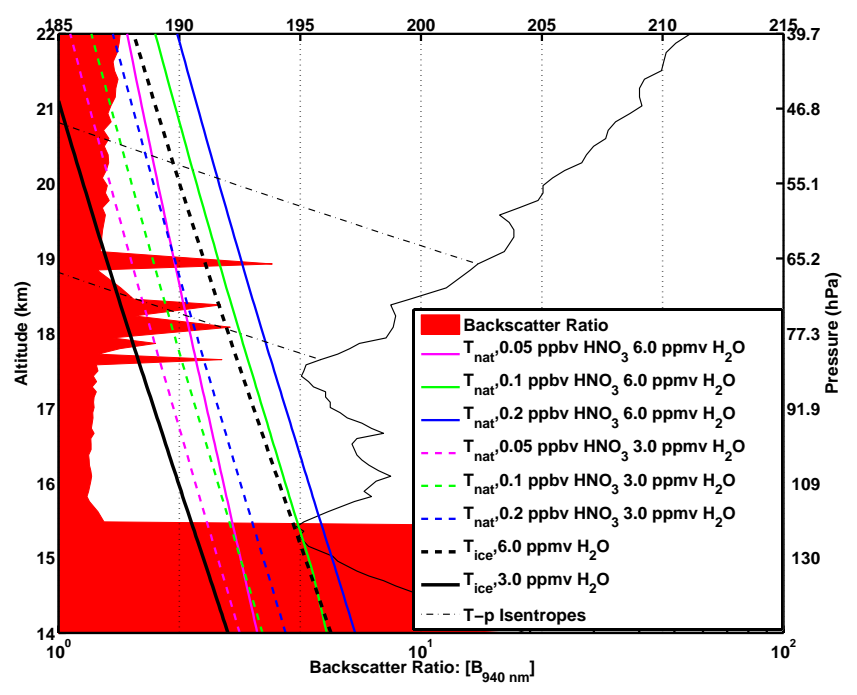

Fig. 7. Filled red curve: Backscattering Ratio as in Fig. 1. Colored curves: Condensation temperatures for NAT. Thick black curves: Condensation temperatures for ice (Frost point temperatures). See legend for different assumptions about water and $\mathrm{HNO}_{3}$ gas phase mixing ratio. Thin black curve: Temperature as in Fig. 1 and thin dot-dashed curves: Isentropes calculated from the pressure profile.

volcanic aerosols. From this we conclude that the particles are not ordinary liquid aerosols, hence most likely solid. At least if the particles were made of ice it would seem unlikely that their radius should be less than a few tenths of a micrometre, since such small ice particles would be quite unstable. So we find that it is reasonable to assume that the radius median lies within $0.2-1.5 \mu \mathrm{m}$ (white ellipse in Fig. 6). Given this radius interval and the measured aerosol backscattering ratio at approximately $2-3$, we are lead to conclude that the number density is in the interval $0.4-10 \cdot 10^{6} \mathrm{~kg}$ air) $)^{-1}$ (or $0.03-1 \mathrm{~cm}^{-3}$ ). The particles were most probably solid, since liquid aerosols activated to water droplets of $0.2-$ $1.5 \mu \mathrm{m}$ would have nucleated and formed ice very quickly. This is also consistent with $\mathrm{O} 2$, from which we can conclude directly, based on the volume depolarization signal, that the measured particles were solid. It is possible that the particles were composed of nitric acid tri-hydrate (NAT). Neither ice or NAT are stable in the dry environment above the TTL. In Fig. 7 the ice frost point temperatures and NAT condensation temperatures are plotted for different reasonable assumptions about water vapor and gas phase $\mathrm{HNO}_{3}$ mixing ratios. We conclude from Fig. 7, that no matter whether the particles at $18.9 \mathrm{~km}$ were made of NAT or ice, the air in which they reside would have to be cooled at least $10 \mathrm{~K}$ along an isentrope in order to reach saturation, if we assume water vapor and $\mathrm{HNO}_{3}$ mixing ratios close to lower stratospheric levels. NAT-particles do have a much longer sublimation time than ice particles, so NATparticles would have the ability to remain present in a non-equilibrium state for several hours. This could explain why the particles had not sublimated at 
the time of observation, but it would still be an open question how these particles were created in - or brought to the lowest stratosphere. Particle "clouds" with number densities in the order of $10^{-5} \mathrm{~cm}^{-3}$ containing nitric acid have been observed recently at the tropical cold point tropopause (Popp et al., 2005). The present observations are at higher altitude and the number density is much larger. Assuming that the particles were composed of NAT, we estimate their $\mathrm{HNO}_{3}$ content to $0.29-4.9 \cdot 10^{-9} \mathrm{~kg}(\mathrm{~kg} \text { air })^{-1}$, which would correspond to a gas phase mixing ratio of $0.13-2.3 \mathrm{ppbv}$, if the particles were fully sublimated. This is of course based on the particle radius interval estimated from Fig. 7.

Typical values of gas phase $\mathrm{HNO}_{3}$ in the tropical tropopause lie around $0.1 \mathrm{ppbv}$ and lower (Popp et al., 2005), which is also the saturation mixing ratio at the temperature minimum of $\mathrm{O} 1$, if one assumes a water vapor mixing ratio of $6.06 \mathrm{ppmv}$. Thus, for an airmass to form an amount of NAT corresponding to $0.13-2.3 \mathrm{ppbv}$, it would require an unexplained abnormally high $\mathrm{HNO}_{3}$ abundance during the nucleation and growth of NAT particles. Jensen and Drdla (2002) have reported localized regions with higher concentration of $\mathrm{HNO}_{3}$ at the tropical tropopause. It cannot be ruled out that the $\mathrm{HNO}_{3}$ concentration may be enhanced sufficiently to produce NAT above convective areas, due to flash induced $\mathrm{NO}_{\mathrm{x}}$ formation in convective systems, but it is not necessary to assume that the particles were composed of NAT in order to explain their occurrence.

\section{Discussion}

\subsection{Origin of high altitude particles}

The most striking feature of $\mathrm{O} 1$ is that there is no sign of local deep convection in the radar images close to the time of observation, as seen in Fig. 2. This makes the particle occurrences somewhat mysterious. We neglect the quite unlikely possibility that the particles were traces of meteorites originating from outside the earth's atmosphere. Such a highly localized event would not leave traces in a large vertical range (note that there is strong shear motion around both measurements).

A more likely explanation would be traces of smoke lifted to the stratosphere by pyro-cumulonimbus clouds. This phenomenon has been observed by Fromm et al. (2006), and also measured by Jost et al. (2004). In fact there is evidence in HALOE, POAM III, SAGE II and SAGE III aerosol data for an anomalous perturbation of the lower stratosphere in January/February 2001, at the time when $\mathrm{O} 2$ were performed, which could originate from such an event. However, the following circumstances makes this explanation somewhat unlikely. First, trajectory calculations (not shown) from $\mathrm{O} 2$ do not match any of the satellite observed aerosol anomalies. Secondly, the observed particle layers of $\mathrm{O} 1$ and $\mathrm{O} 2$ had very limited horizontal extend. In the case of $\mathrm{O} 1$ it is evident that the layer was not present on the sondes ascent $30 \mathrm{~min}$ before and in the case of $\mathrm{O} 2$ the particles were only present for $15 \mathrm{~min}$, thus a reasonable guess is that the cloud was less than $10 \mathrm{~km}$ in horizontal extension. With the vertical thickness of approximately $2 \mathrm{~km}$, the "particle-cloud" cannot be more than a few hours old, since a cloud of this shape would be extended fast horizontally due to the the large wind shear above the TTL. It should be noted that there were no large forest fires in the area. Likewise it seems unlikely that the particles are traces of volcanic eruptions, which presumably would have resulted in a smooth layer of great extent. We cannot rule out that aged smoke or maybe dessert dust residing in troposphere or TTL somehow had been lofted into the stratosphere, for instance by a convective overshoot. Keeping the possibility of non-volatile particles in mind we now turn to consider two other possibilities for the origin of the particles detected in O1, namely gravity waves or deep convective outflow.

Suppose that gravity waves of short wavelength had decreased the temperature locally, so that some air parcels in the lowest stratosphere became sufficiently supersaturated with respect to ice for ice nucleation to occur. This is similar to the mechanism proposed by Potter and Holton (1995). We can estimate that a temperature drop of more than $10 \mathrm{~K}$ would be required in order to reach the ice nucleation temperature. The ice nucleation temperature lies a few Kelvin below the frost point (dashed line in Fig. 1 or thick dashed black line in Fig. 7) because a certain amount of supersaturation is required, for nucleation to occur (Koop et al., 2000). Wave cooling would be adiabatic; it would follow an isentrope (dash-dotted lines) in Figs. 1, 4 and 7, and reach $\mathrm{T}_{\text {ice }}$ at higher altitude. One possibility would be waves driven by wind shear (Kelvin Helmholtz-instability). But even though the wind shear was quite large (up to $25(\mathrm{~m} / \mathrm{s}) / \mathrm{km}$ close to $18 \mathrm{~km}$ altitude), the Richardson number (de Silva et al., 1996) stays well above 2 , which implies that conditions do not allow for evolution of Kelvin Helmholtz-instabilities at this altitude. The most likely source for waves would be the thunderstorms, located 100-200 km away from the observation site. Tropical thunderstorms are known to induce gravity waves (Song et al., 2003; Lane et al., 2001; Santacesaria et al., 2003; Garrett et al., 2006). Comparison between ascent temperature profile and descent temperature profile (separated by $30 \mathrm{~min}$ ) shows that there are actually fluctuations in the temperature around the TTL, but the difference between ascent and descent temperature is below $2 \mathrm{~K}$ at all levels, which is far from the (at least) $10 \mathrm{~K}$ needed just to get saturation. Thus, in the temperature profile recorded on board the backscatter payload, we find no signature of gravity waves, and therefore the possibility of "wave generated" particles seems unlikely.

In a more likely scenario the particles were lifted into the stratosphere by a distant thunderstorm, accompanied by a large amount of water vapor, and then transported to the point of observation. This hypothesis can be rationalized 
by a closer inspection of the radar image sequence covering the late afternoon leading up to the measurements. Trajectories calculated from the ECMWF operational analysis lead to a group of thunderstorms in the South Atlantic Convergence Zone 200-240 km east-northeast of Bauru 5-6h earlier (Figs. 2 and 3). Exploring different combinations of particle fall-speeds and trajectory starting points, it turns out that the forward trajectories calculated from a specific thunderstorm at 16:46 local time (19:46 UT 20 February), $215 \mathrm{~km}$ E.N.E. from Bauru, hits the point of observation (01:20 UT 21 February) when the particles were observed. The match can be obtained with different combinations of start-altitudes and particle fall speed. Fall speeds in the range $0.0-0.1 \mathrm{~m} / \mathrm{s}$ were tested, corresponding to particle radii of $0-17 \mu \mathrm{m}$. A fall speed of $0.028 \mathrm{~m} \mathrm{~s}^{-1}$ corresponding to a particle radius of approximately $10 \mu \mathrm{m}$ is chosen as an example and shown in Figs. 2 and 3. A manual inspection of echo tops at the $-5 \mathrm{dBZ}$ radar reflectivity threshold shows that the storm turret goes up to at least $20( \pm 1) \mathrm{km}$. There may have been more ice crystals above this height, but due to the long range $(>200 \mathrm{~km})$ and their low concentration, they would have been below the detection limit of the Bauru radar. Assuming that the particles were composed of ice, they could not be much larger than $10 \mu \mathrm{m}$, since they would have to reside in air masses which were saturated or supersaturated with respect to ice during the process in order not to sublimate within a few minutes (Larsen, 2000). This means that the particles would have to stay within humid tropospheric air which entered and mixed with the stratosphere along with the particles, without sedimenting out.

\subsection{Mixing process}

The ozone profile recorded in situ simultaneously with the aerosol backscattering signal shows no sign of tropospheric values in the air masses close to the observation, which might seem inconsistent with the hypothesized scenario. However, one has to bear in mind that tropospheric air mixed with stratospheric air at a given altitude, will have to descend a certain distance to reach the level of neutral buoyancy (Danielsen, 1982). Let $\alpha$ be the fraction of tropospheric air, and $(1-\alpha)$ the fraction of stratospheric air in the mixed air parcel. Assuming adiabatic transport and no chemical $\mathrm{O}_{3}$ production we can write two different relations for the mixing process

$$
\begin{aligned}
\chi_{t} \alpha+\chi_{s}(1-\alpha) & =\chi_{m} \\
\theta_{t} \alpha+\theta_{s}(1-\alpha) & =\theta_{m},
\end{aligned}
$$

where $\theta$ is the potential temperature, $\chi$ the ozone mixing ratio, and the subscripts $t, s$ and $m$ refer to "tropospheric", "stratospheric" and "mixed" air. While Eq. (1) is self explanatory, Eq. (2) is achieved by considering the physical process of mixing: When two air parcels, $t$ and $s$ - of respective mass coefficients $\alpha$ and $(1-\alpha)$ and potential temperatures $\theta_{t}$ and $\theta_{s}$ mix, they must be transported to the same pressure level. Here we assume that this happens through an adiabatic ascent of tropospheric air $(t)$, i.e., the potential temperatures of the two air parcels are conserved. As they reach the same pressure $p$, their potential temperatures are given by $\theta_{t}=T_{t}\left(\frac{p_{0}}{p}\right)^{\kappa}$ and $\theta_{s}=T_{s}\left(\frac{p_{0}}{p}\right)^{\kappa}$, where $\kappa=R / c_{p}$. After the mixing process the potential temperature is determined by the temperature of the mix: $\theta_{m}=\left(\alpha T_{t}+(1-\right.$ $\left.\alpha) T_{s}\right)\left(\frac{p_{0}}{p}\right)^{\kappa}=\alpha \theta_{t}+(1-\alpha) \theta_{s}$, which is simply a weighted mean of their respective potential temperatures. Actually the rising air parcel loses some of its water vapor content during the process due to condensation, so formally one should use the equivalent potential temperature instead of $\theta$ to form relation 2, but the role of condensation in terms of heating is insignificant due to low water vapor content in the TTL. It is not possible to close the Eqs. (1) and (2), but from the linearity between ozone and potential temperature in the lower stratosphere (see Fig. 8) we can reduce the number of unknowns to only three in Eqs. (1) and (2). This enables us to deduce a relation between the potential temperature $\theta_{t}$ at the altitude where the tropospheric air originates, and the tropospheric air mixing coefficient $\alpha$. The relation is plotted as a thick red area in Fig. 8. If the entraining air came from below the lapse rate tropopause at $15 \mathrm{~km}(\theta=352 \mathrm{~K})$, we can estimate that the mixed air is composed of $1 / 5$ tropospheric air, and 4/5 stratospheric air. The turret must have reached an altitude of at least $19.7 \mathrm{~km}(\theta=462 \mathrm{~K})$ in order to obtain neutral buoyancy at $18.9 \mathrm{~km}$. It can be seen from Fig. 3 that the storm $\mathrm{C} 1$ exceeded $20( \pm 1) \mathrm{km}$ in height, thus confirming this rationale.

\subsection{Turret altitude}

The observation of particles on 21 February 2004, 01:19 UT at 17.7 to $18.9 \mathrm{~km}$ can be rationalized if deep convection can go up to at least $19.7 \mathrm{~km}$. In the literature there are several observations of turrets reaching this altitude (Alcala and Dessler, 2002; Adler and Mack, 1986; Ebert and Holland, 1992; Simpson et al., 1993). As shown in Sect. 2, the situation for the 14 February 2001 observation was very similar. It will be up to future campaigns to possibly confirm and explore such events.

\subsection{Hydration}

At the time when the tropospheric air was lifted through the TTL it must have been cooled considerably; thus, it had to carry practically all the water that it contained at the observation time as ice particles. Assuming that the air surrounding the particles was saturated at the observation time we can asses the total water content: The gas phase water mixing ratio $q_{\text {vap }}$ is calculated from the temperature at $18.9 \mathrm{~km}$ altitude (see Fig. 1), and the solid phase water mixing ratio is estimated by assuming that the ice particle median radius is 


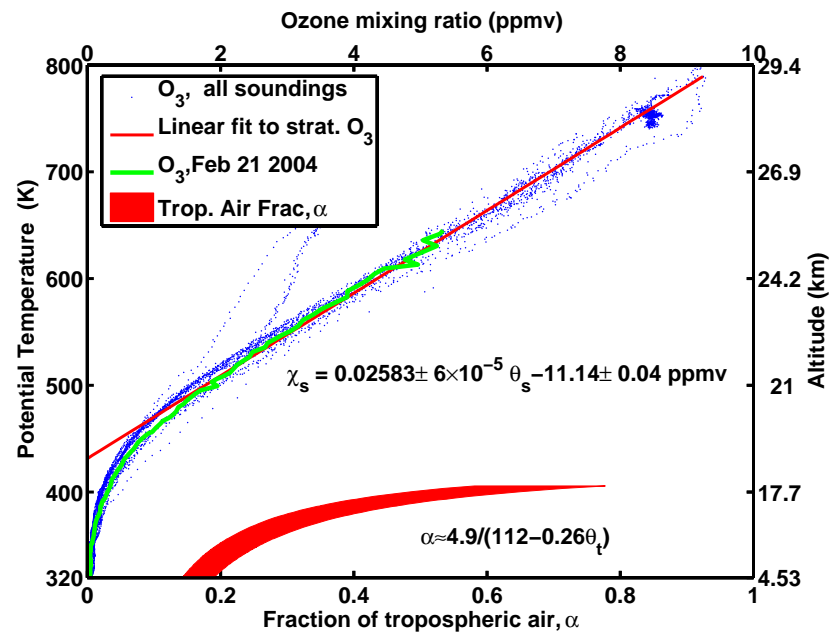

Fig. 8. Blue dots: Scatter plot of potential temperature versus ozone volume mixing ratio measured through 10 independent soundings over Bauru in February 2004. Ozone mixing ratio depends linearly on potential temperature between 450 and $750 \mathrm{~K}$. Red curve: Linear fit to lower stratospheric ozone. Thick red area: Tropospheric air mixing coefficient calculated by assuming that tropospheric air is originating from different altitudes. The width of the area indicates the uncertainty of the estimated $\alpha$ - value, calculated by propagating the standard errors off the line coefficients in the $\chi-\theta$ relation, through the solution to Eqs. (1) and (2)

$1 \mu \mathrm{m}$, (the exact size does not matter for this purpose since most water is found to be in the gas phase)

$q_{\text {tot }}=q_{\text {vap }}+q_{\text {ice }}=2.2 \cdot 10^{-5}+4 \cdot 10^{-8} \mathrm{~kg}(\mathrm{~kg} \text { air })^{-1}$. Assuming now that the tropospheric and stratospheric air were mixed with the ratio 1:4, as estimated in Sect. 4.2, it follows that the number density in the entraining tropospheric air must have been at least 5 times $0.4-10 \times 10^{6}(\mathrm{~kg} \text { air })^{-1}$ (5 times the number density interval estimated in Sect. 3). Likewise the total water content must have been larger than $q_{\text {tot }}$, approximately $1.0 \cdot 10^{-4} \mathrm{~kg}(\mathrm{~kg} \text { air })^{-1}$, in the entraining tropospheric air. Distributed equally among the present particles, it leads to a particle radius of $7-23 \mu \mathrm{m}$ at the time of detrainment from the convection turret. This number is highly uncertain, since larger particles may have settled out of the mixed air parcel, and smaller particles may have sublimated. It would correspond to a vertical velocity of at least 0.01 to $0.1 \mathrm{~m} \mathrm{~s}^{-1}$ in order to lift the particles, which is easily achieved.

If the particles were composed of ice, which we have argued is the most likely case (Sect. 3), there is no doubt that the studied overshoot effectively hydrated the stratosphere. During the detraining process, when the air masses were mixed, ice particles lost most of their water content by sublimation, and the ice particles, which were still present at the observation time, were bound to sublimate in the lower stratosphere as they sedimented out of their saturated environment, or as their environment was further diluted with dryer stratospheric air. Eventually the intruded water would be brought further into the stratosphere due to Brewer Dobson circulation. We note, that even though the rarity of turrets penetrating deep into the lower stratosphere leaves little potential for dehydration, they may actually have larger hydration potential. For example in the case discussed above, the intruding air masses had water contents which were more than an order of magnitude larger than the typical stratospheric air, and thus had ability to hydrate a large airmass. In the other observation, $\mathrm{O} 2$, the lidar backscatter ratio at $532 \mathrm{~nm}$ is twice as large (consequently the equivalent backscatter ratio at $940 \mathrm{~nm}$ would be even larger) and the particles were found at slightly higher altitude. In other respects the signatures of the two observations are quite similar, so there is reason to assume that $\mathrm{O} 2$ is also an indication of hydration of the lower stratosphere. The importance of this kind of process for the stratospheric water vapor budget cannot be deduced without knowledge about the frequency of such deep convective events.

Held et al. (2003) studied the frequency of radar echoes at the $10 \mathrm{dBZ}$ reflectivity threshold penetrating through the tropopause for seven consecutive Februaries. They found, that at least one or more storms within the $240 \mathrm{~km}$ radar range reached the lower stratosphere on an average of $33 \%$ of the days, with a maximum frequency of more than 50\% during February 1998 and 1999. Subsequently, Gomes and Held (2004) studied the echo top (10 dBZ radar reflectivity) distribution of storms during a ten-year period and found that $17 \%$ of all storms within the $240 \mathrm{~km}$ radar range exceeded $15 \mathrm{~km}$, commonly reaching up to $17-19 \mathrm{~km}$ amsl. In a global satellite based study Liu and Zipser (2005) reports a maximum occurrence of overshooting cloud tops (altitude $\approx 420 \mathrm{~K}$ ) over continents, with a local maximum frequency over Southern Brazil in December to February. According to the authors, their estimate of $0.005 \%$ total overshooting area is an underestimate due to their $20 \mathrm{dBZ}$ reflectivity threshold. In a more resent analysis of tropical cloud altitudes measured by the so called "GLAS lidar-in-space" (Dessler et al., 2006) $0.34 \%$ of thick clouds and $3.1 \%$ of thin clouds are reported to be located above the $377 \mathrm{~K}$ potential temperature level. It would be premature, at this stage, to quantify the impact of these very deep convective events on the stratospheric water budget, without more information about their frequency and their microphysics.

We cannot rule out the possibility that the particles were partly composed of NAT or soot. There are several possibilities for the internal particle structure. For example, one possibility would be that the particles were composed of an ice kernel coated with NAT, implying that they would not need to reside in air saturated with respect to water vapor over ice or NAT. If this is the case, we cannot be that specific about the water content of the air surrounding the particles, since we do not know its thermodynamic history. It is too speculative to elaborate further on such details with the information that we have at hand. However, we can conclude that the intruding air must act hydrating rather than dehydrating to the 


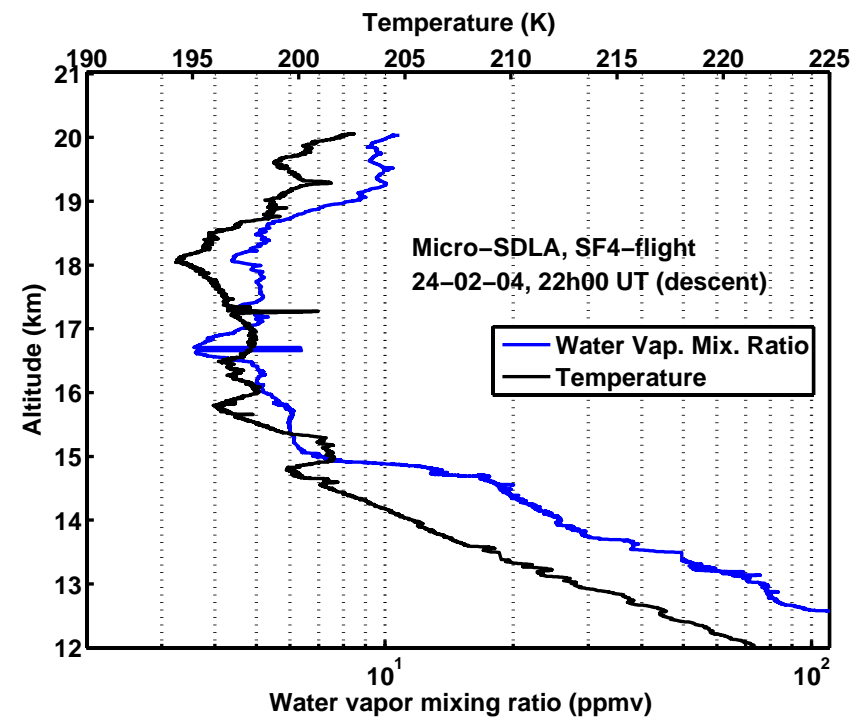

Fig. 9. The $\mathrm{H}_{2} \mathrm{O}$ vertical mixing ratio profile measured in situ by the micro-SDLA balloon borne diode laser spectrometer (Durry et al., 2004) from Bauru on 24 February 2004 during the HIBISCUS campaign. Large amounts of water vapor were surprisingly observed above the TTL in the $18.5 \mathrm{~km}$ to $20 \mathrm{~km}$ altitude region. Possibly these large amounts of $\mathrm{H}_{2} \mathrm{O}$ could be remnants of humid tropospheric air injected by deep convection into the lower stratosphere. See text for more details.

lower stratosphere, due to the water bound in ice and NAT, though the hydration potential is unknown.

\subsection{Further observations}

Finally, we would like to present a striking observation of large amounts of water vapor above the TTL achieved during the HIBISCUS campaign, which could be a further evidence for the presence of solid particles in the lower stratosphere. There are certain reservations to this measurement due to potential instrumental artifacts. Nevertheless we believe it is worthwhile mentioning these unusual $\mathrm{H}_{2} \mathrm{O}$ observations to support the discussion, with the caveat, of the instrumental reservations clearly explained here, kept in mind. It is important to emphasize that our conclusions from the particle measurements are completely independent of this observation.

Four days after O1, on 24 February 2004, 22:00 UT, a water vapor profile was measured in situ from Bauru by the balloon borne micro-SDLA sensor. The $\mathrm{H}_{2} \mathrm{O}$ concentration was determined in situ during the descent of the gondola by diode laser absorption spectroscopy at 1.39 micron with an inaccuracy of a few percent and a temporal resolution of four samples per second (Durry et al., 2004). A discussion of the micro-SDLA $\mathrm{H}_{2} \mathrm{O}$ data in the UT and the TTL is presented in Durry et al. (2006). We focus here on the upper part of the flight above the TTL, where a surprisingly high water vapor concentration was observed during the descent of the

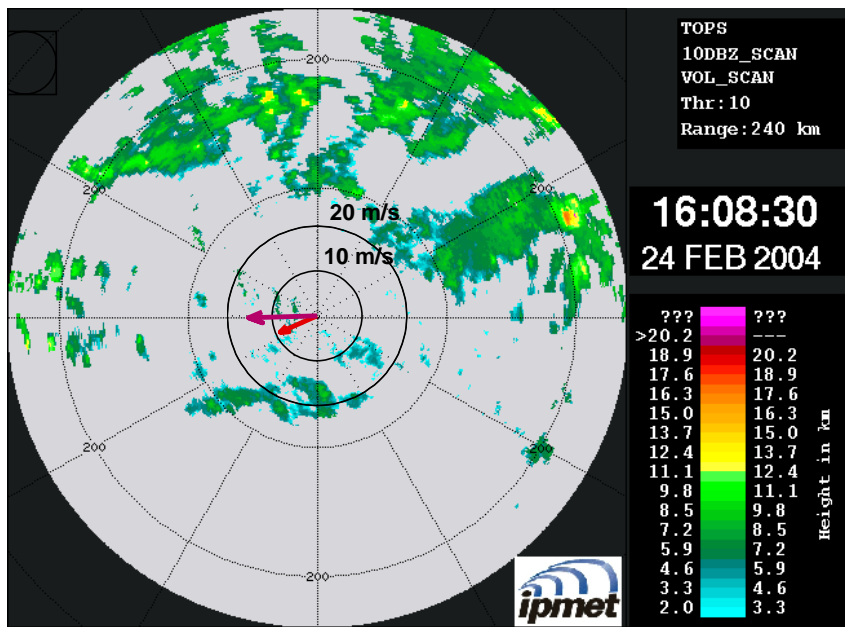

Fig. 10. A snapshot of the cloud top altitude recorded from the Bauru radar late afternoon $6 \mathrm{~h}$ before the water vapor mixing ratio profile in Fig. 9 was observed. There is plenty of deep convection going on east of Bauru, and only a small fraction of it is within the radar image. The inserted arrows show the wind field at 17, 19 and $21 \mathrm{~km}$, over Bauru, from ECMWF operational analysis. Please note that the 2 bold circles delineate wind speed in $\mathrm{m} / \mathrm{s}$, while the outer circles indicate the 100 and $200 \mathrm{~km}$ distance, respectively, from the Bauru radar. In fact the convective overshoot from which the probed air originates may well be located outside the radar range.

balloon as reported in Fig. 9. The water vapor mixing ratio increases from $5 \mathrm{ppmv}$ at $18.5 \mathrm{~km}$ to $9-10 \mathrm{ppmv}$ at $20 \mathrm{~km}$, which is far above the usual values of 5 ppmv expected in the lower stratosphere. The flight happened under meteorological conditions quite similar to those of $\mathrm{O} 1$, as is seen from Fig. 10. The large amounts of water are likely due to humid tropospheric air being advected with a north-easterly flow from a cyclonic vortex at high altitude located over the coastal region of northeast Brazil (State of Bahia), and entering the stratosphere by deep convection, as supported by observations from the Bauru radar.

Nonetheless, a competing explanation for this observation is pollution of the measurement by water vapor out-gassing from the balloon envelope at the beginning of the slow descent where it is known that the balloon may oscillate a little (Durry and Megie, 2000; Durry et al., 2002) until the descent speed has stabilized. Nevertheless, in the HIBISCUS flights, the descent was achieved with a day-to-night transition (the balloon temperature decreases at sunset initiating thereby the slow descent), instead of using a valve. This results in a much more smooth slow descent with little oscillations. Hence, we have not observed the usual spikes of water vapor which indicates the vertical oscillations of the balloons (Durry et al., 2002). There is no further clear evidence of contamination from the examination of the GPS information and temperature data. Furthermore, for the HIBISCUS flights, small balloons $\left(3000 \mathrm{~m}^{3}\right)$ were used to carry the micro-SDLA up to $22 \mathrm{~km}$, instead of the usual large balloons $\left(50000 \mathrm{~m}^{3}\right)$ 
implemented to probe the stratosphere. A smaller diameter of the balloon strongly reduces the corruption effect. Therefore, the issue of the significance of these striking large amounts of water vapor is still open. We believe that it could be residues of deep convection where humid tropospheric air masses are mixed with stratospheric air. The conditions are present for this to be the case. As shown in Fig. 10 there was a lot of convective activity east of Bauru in the afternoon, and with the easterly around $18-20 \mathrm{~km}$, shown with arrows, it is very likely, that overshooting air was transported over Bauru during the evening.

\section{Conclusions}

In two cases during the HIBISCUS campaigns solid particles were observed at very high altitudes in the lower stratosphere in the South Atlantic Convergence Zone. These observations indicate that deep convection can reach altitudes of at least up to $20.8 \mathrm{~km}$. In one of the observations it was possible to make a rough estimate of the particle radii to be in the order of $0.2-1.5 \mu \mathrm{m}$, and the number density to be $0.03-1 \mathrm{~cm}^{-3}$. In the other observation it could be concluded that the particles where solid. Through a study of the local meteorological situation it was in one case concluded that the air mass where the particles occur was most likely originating from a specific thunderstorm seen in radar images $5.5 \mathrm{~h}$ before the observation, and that it must have carried a considerable amount of ice-water into the stratosphere to maintain saturation of water vapor with respect ice while mixing with stratospheric air. We have argued that due to their estimated size and number density, the particles could be composed of ice, which implies that airmasses with a total water vapor mixing ratio of at least $160 \mathrm{ppmv}$ entered the stratosphere along with the particles. No matter whether the particles consisted of pure ice or were partly composed of NAT, we are lead to conclude that their presence is an indication of hydration through deep convection. If the particles were non-volatile, e.g. soot, the possibility of hydration would still be there, but we would not be able to conclude that it had happened. We find additional evidence for this sort of process in water vapor measurements from the same location, showing enhanced water vapor mixing ratios, up to around $10 \mathrm{ppmv}$, in the lowest stratosphere during similar meteorological conditions.

Acknowledgements. The authors gratefully acknowledge the comments, suggestions and data provided by M. Fromm, regarding the impact of forest fires on the lower stratosphere. We would like to thank A. Garnier (CNRS) and the rest of the HIBISCUS team. We also thank the coordinators of the TroCCiBras Project and the IPMet staff for providing the infrastructure support during the campaign. This work was supported by the Danish National Space Board (OFR), the EC project HIBISCUS and the integrated EC project SCOUT-O3. One of the authors, J. M. Rosen, was supported by the U. S. National Science Foundation.
Edited by: R. MacKenzie

\section{References}

Adler, R. F. and Mack, R. A.: Thunderstorm Cloud Top Dynamics as Inferred from Satellite Observations and a Cloud Top Parcel Model., J. Atmos. Sci., 43, 1945-1960, 1986.

Alcala, C. M. and Dessler, A. E.: Observations of deep convection in the tropics using the Tropical Rainfall Measuring Mission (TRMM) precipitation radar, J. Geophys. Res. (Atmospheres), $107,17,2002$.

Danielsen, E. F.: A dehydration mechanism for the stratosphere, Geophys. Res. Lett., 9, 605-608, 1982.

de Silva, I. P. D., Fernando, H. J. S., Eaton, F., and Hebert, D.: Evolution of Kelvin-Helmholtz billows in nature and laboratory, Earth Planet. Sci. Lett., 143, 217-231, 1996.

Dessler, A. E., Palm, S. P., and Spinhirne, J. D.: Tropical cloudtop height distributions revealed by the Ice, Cloud, and Land Elevation Satellite (ICESat)/Geoscience Laser Altimeter System (GLAS), J. Geophys. Res. (Atmospheres), 111, D12 215, 2006.

Di Donfrancesco, G., Cairo, F., Buontempo, C., Adriani, A., Viterbini, M., Snels, M., Morbidini, R., Piccolo, F., Cardillo, F., Pommereau, J. P., and Garnier, A.: Balloonborne lidar for cloud physics studies, Appl. Opt., 45, 5701-5708, 2006.

Durry, G. and Megie, G.: In situ measurements of $\mathrm{H}_{2} \mathrm{O}$ from a stratospheric balloon by diode laser direct-differential absorption spectroscopy at $1.39 \mu \mathrm{m}$, Appl.Opt., 39, 5601-5608, 2000.

Durry, G., Hauchecorne, A., Ovarlez, J., Ovarlez, H., Pouchet, I., Zeninari, V., and Parvitte, .: In situmeasurement of $\mathrm{H}_{2} \mathrm{O}$ and $\mathrm{CH}_{4}$ with telecommunication laser diodes in the lower stratosphere: dehydration and indication of a tropical air intrusion at mid-latitudes, J. Atmos. Chem., 43, 2002.

Durry, G., Amarouche, N., Zninari, V., Parvitte, B., Lebarbu, T., and Ovarlez, J.: In situ sensing of the middle atmosphere with balloonborne near-infrared laser diodes, Spectrochim. Acta A, 60, 3371-3379, 2004.

Durry, G., Huret, N., Hauchecorne, A., Marecal, V., Pommereau, J. P., Jones, R. L., Held, G., Larsen, N., and Renard, J. B.: Isentropic advection and convective lifting of water vapor in the UT LS as observed over Brazil (22 S) in February 2004 by in situ high-resolution measurements of $\mathrm{H}_{2} \mathrm{O}, \mathrm{CH}_{4}, \mathrm{O}_{3}$ and temperature, Atmos. Chem. Phys. Discuss., 6, 12 469-12 501, 2006.

Ebert, E. E. and Holland, G. J.: Observations of Record Cold CloudTop Temperatures in Tropical Cyclone Hilda (1990), Monthly Weather Review, 120, 1992.

Folkins, I., Loewenstein, M., Podolske, J., Oltmans, S. J., and Proffitt, M.: A barrier to vertical mixing at $14 \mathrm{~km}$ in the tropics: Evidence from ozonesondes and aircraft measurements, J. Geophys. Res., 104, 22 095-22 102, 1999.

Fromm, M., Tupper, A., Rosenfeld, D., Servranckx, R., and McRae, R.: Violent pyro-convective storm devastates Australia's capital and pollutes the stratosphere, Geophys. Res. Lett., 33, 5815-+, 2006.

Fueglistaler, S. and Haynes, P. H.: Control of interannual and longer-term variability of stratospheric water vapor, J. Geophys. Res. (Atmospheres), 110, D24 108, 2005.

Fueglistaler, S., Wernli, H., and Peter, T.: Tropical troposphereto-stratosphere transport inferred from trajectory calculations, 
J. Geophys. Res. (Atmospheres), 109, 3108, 2004.

Garrett, T. J., Dean-Day, J., Liu, C., Barnett, B., Mace, G., Baumgardner, D., Webster, C., Bui, T., Read, W., and Minnis, P.: Convective formation of pileus cloud near the tropopause, Atmos. Chem. \& Phys., 6, 1185-1200, 2006.

Gettelman, A., Holton, J. R., and Douglass, A. R.: Simulations of water vapor in the lower stratosphere and upper troposphere, J. Geophys. Res. (Atmospheres), 105, 9003-9024, 2000.

Gomes, A. M. and Held, G.: Determinação e avaliação do parâmetro densidade VIL para alerta de tempestades., in XIII Congresso Brasileiro de Meteorologia, 29 August-3 September, 12pp, SBMET, Fortaleza, 2004.

Hartmann, D. L., Holton, J. R., and Fu, Q.: The heat balance of the tropical tropopause, cirrus, and stratospheric dehydration, Geophys. Res. Lett., 28, 1969-1972, 2001.

Held, G., Gomes, A. M., and Figuiredo, J. C.: Statistics of echo top and VIL density and local synoptic situations in São Paolo State, in TROPIC Workshop, Wessling 14-16 May 2003, http: //www.pa.op.dlr.de/troccinox/private/meetings/TROPIC/,2003.

Holton, J. R. and Gettelman, A.: Horizontal transport and the dehydration of the stratosphere, Geophys. Res. Lett., 28, 2799-2802, 2001.

Holton, J. R., Haynes, P. H., McIntyre, M. E., Douglass, A. R., Rood, R. B., and Pfister, L.: Stratosphere-troposphere exchange, Reviews of Geophysics, 33, 403-439, 1995.

Jensen, E. and Drdla, K.: Nitric acid concentrations near the tropical tropopause: Implications for the properties of tropical nitric acid trihydrate clouds, Geophys. Res. Lett., 29, 62-1, 2002.

Jensen, E. and Pfister, L.: Transport and freeze-drying in the tropical tropopause layer, J. Geophys. Res. (Atmospheres), 109, 2207, 2004.

Jensen, E., Pfister, L., Ackerman, A., and Toon, O.: A conceptual model of the dehydration of air due to freeze-drying by optically thin, laminar cirrus rising slowly across the tropical tropopause, J. Geophys. Res., 106, 17 237-52, 2001.

Jost, H.-J., Drdla, K., Stohl, A., Pfister, L., Loewenstein, M., Lopez, J. P., Hudson, P. K., Murphy, D. M., Cziczo, D. J., Fromm, M., Bui, T. P., Dean-Day, J., Gerbig, C., Mahoney, M. J., Richard, E. C., Spichtinger, N., Pittman, J. V., Weinstock, E. M., Wilson, J. C., and Xueref, I.: In-situ observations of mid-latitude forest fire plumes deep in the stratosphere, Geophys. Res. Lett., 31, 11 101-+, 2004.

Knollenberg, R. G., Kelly, K., and Wilson, J. C.: Measurements of high number densities of ice crystals in the tops of tropical cumulonimbus, J. Geophys. Res., 98, 8639-8664, 1993.

Koop, T., Luo, B., Tsias, A., and Thomas, P.: Water activity as the determinant for homogeneous ice nucleation in aqueous solutions., Nature, 406, 611-614, 2000.

Küpper, C., Thuburn, J., Craig, G. C., and Birner, T.: Mass and water transport into the tropical stratosphere: A cloud-resolving simulation, J. Geophys. Res. (Atmospheres), 109, $10111,2004$.

Lane, T. P., Reeder, M. J., and Clark, T. L.: Numerical Modeling of Gravity Wave Generation by Deep Tropical Convection., J. Atmos. Sci., 58, 1249-1274, 2001.

Larsen, N.: Polar Stratospheric Clouds, Microphysical and Optical Models, Scientific Report 00-06, Danish Meteorological Institute, Copenhagen, 2000.

Liu, C. and Zipser, E. J.: Global distribution of convection penetrating the tropical tropopause, J. Geophys. Res. (Atmospheres),
110, D23 104, 2005.

Mishchenko, M. I. and Travis, L. D.: Capabilities and limitations of a current FORTRAN implementation of the T-matrix method for randomly oriented, rotationally symmetric scatterers - Computational Methods, J. Quant. Spectrosc. Radiat. Transfer, 60, 309-324, 1998.

Moyer, E. J., Irion, F. W., Yung, Y. L., and Gunson, M. R.: ATMOS stratospheric deuterated water and implications for tropospherestratosphere transport, Geophys. Res. Lett., 23, 2385-2388, 1996.

Newell, R. E. and Gould-Stewart, S.: A Stratospheric Fountain?., J. Atmos. Sci., 38, 2789-2789, 1981.

Pommereau, J.-P.: HIBISCUS Homepage, www.aerov.jussieu.fr/projet/HIBISCUS/en/many/index.html, 2004.

Popp, P. J., Marcy, T. P., Jensen, E. J., Kaercher, B., Fahey, D. W., Gao, R. S., Thompson, T. L., Rosenlof, K. H., Richard, E. C., Herman, R. L., Weinstock, E. M., Smith, J. B., May, R. D., Voemel, H., Wilson, J. C., Heymsfield, A. J., Mahoney, M. J., and Thompson, A. M.: The observation of nitric acid-containing particles in the tropical lower stratosphere, Atmos. Chem. Phys. Discuss, 5, 10098 - 10 124, 2005.

Potter, B. E. and Holton, J. R.: The Role of Monsoon Convection in the Dehydration of the Lower Tropical Stratosphere., J. Atmos. Sci., 52, 1034-1050, 1995.

Rosen, J. M. and Kjome, N. T.: Backscattersonde - A new instrument for atmospheric aerosol research, Applied Optics, 30, 1552-1561, 1991.

Santacesaria, V., Carla, R., MacKenzie, R., Adriani, A., Cairo, F., Didonfrancesco, G., Kiemle, C., Redaelli, G., Beuermann, J., Schiller, C., Peter, T., Luo, B., Wernli, H., Ravegnani, F., Ulanovsky, A., Yushkov, V., Sitnikov, N., Balestri, S., and Stefanutti, L.: Clouds at the tropical tropopause: A case study during the APE-THESEO campaign over the western Indian Ocean, J. Geophys. Res. (Atmospheres), 108, 1-1, 2003.

Schreiner, J., Voigt, C., Weisser, C., Kohlmann, A., Mauersberger, K., Deshler, T., Kröger, C., Rosen, J., Kjome, N., Larsen, N., Adriani, A., Cairo, F., Di Donfrancesco, G., Ovarlez, J., Ovarlez, H., and Dörnbrack, A.: Chemical, microphysical, and optical properties of polar stratospheric clouds, J. Geophys. Res. (Atmospheres), 108, 56-1, 2003.

Sherwood, S. C. and Dessler, A. E.: A Model for Transport across the Tropical Tropopause, J. Atmos. Sci., pp. 765-779, 2001.

Simpson, J., Keenan, T. D., Ferrier, B., Simpson, R. H., and Holland, G. J.: Cumulus Mergers in the Maritime Continent Region, Meteorology and Atmospheric Physics, 51, 73-99, 1993.

Song, I.-S., Chun, H.-Y., and Lane, T. P.: Generation Mechanisms of Convectively Forced Internal Gravity Waves and Their Propagation to the Stratosphere., J. Atmos. Sci., 60, 1960-1980, 2003.

Wu, D. L., Read, W. G., Dessler, A. E., Sherwood, S. C., and Jiang, J. H.: UARS/MLS Cloud Ice Measurements: Implications for $\mathrm{H}_{2} \mathrm{O}$ Transport near the Tropopause., J. Atmos. Sci., 62, 518530, 2005. 